Diyala Journal

ISSN 1999-8716

of Engineering

Printed in Iraq

Sciences

Vol. 06, No. 02, pp. 9-20, June 2013

\title{
FLEXURAL CAPACITIES OF REINFORCED CONCRETE TWO-WAY BUBBLEDECK SLABS OF PLASTIC SPHERICAL VOIDS
}

\author{
Amer M. Ibrahim ${ }^{1}$, Nazar K. Ali ${ }^{2}$, Wissam D. Salman ${ }^{3}$ \\ ${ }^{1,3}$ Engineering College, Diyala University, ${ }^{2}$ Engineering College, Baghdad University
}

(Received:30/4/2012; Accepted:7/6/2012)

\begin{abstract}
This paper presents the flexural capacities of R.C two way hollow slabs of plastic spherical voids, also known as BubbleDeck slab system. Recently, various types of slab systems which can reduce the self-weight of slabs have been studied as the height and width of building structures rapidly increase ${ }^{(1)}$. A biaxial hollow slab system is widely known as one of the effective slab systems which can reduce the self-weight of slabs ${ }^{(1)}$. A BubbleDeck slab has a two-dimensional arrangement of voids within the slabs to reduce selfweight ${ }^{(2)}$. The behavior of BubbleDeck slabs is influenced by the ratio of bubble diameter to slab thickness. To verify the flexural behavior of this BubbleDeck slab such as ultimate load, deflection, concrete compressive strain and crack pattern, two-dimensional flexural tests were tested by using special loading frame. Six test of specimens were used. Two were a conventional RC slab and four were BubbleDeck slabs having void diameter to slab thickness ratios of $(0.51,0.64$ and 0.80$)$. Results have shown that the crack pattern and flexural behavior depend on the void diameter to slab thickness ratio. The ultimate load capacities for BubbleDeck slabs having bubble diameter to slab thickness of $\left(0 .{ }^{\circ} 1\right.$ and 0.64$)$ were the same of solid slabs, while when bubble diameter to slab thickness of $(0.80)$ the ultimate capacities were reduced by about (10\%).
\end{abstract}

Keywords:- : BubbleDeck slab, Flexural test of two-way slab, Plastic sphere.

\section{INTRODUCTION}

In building constructions, the slab is a very important structural member to make a space. And the slab is one of the largest member consuming concrete ${ }^{(1)}$. In a general way, the slab was designed only to resist vertical load. However, as people are getting more interest of residential environment recently, noise and vibration of slab are getting more important ${ }^{(3)}$. In 
addition, as the span is increased, the deflection of the slab is also increased. Therefore, the slab thickness should be increase. Increasing the slab thickness makes the slabs heavier, and will increased column and foundations size. Thus, it makes buildings consuming more materials such as concrete and steel reinforcement ${ }^{(4)}$.

To avoid these disadvantages which were caused by increasing of self-weight of slabs, the BubbleDeck slab system, also known as void slab, was suggested. This system consists of hollow plastic spheres cast into the concrete to create a grid of void forms inside the slab and have a major contribution to the objective of sustainable building ${ }^{(5)}$, by:-

- Saving on the use of primary raw materials, the flexibility offered in the layout of the building and the making of passages and recesses and, finally: in the event of demolition a substantially smaller amount of concrete granulate and recyclable plastic spheres which do not adhere to the concrete ${ }^{(5)}$.

- Smaller amounts of concrete have to be transported by road and smaller amounts of cement, sand and gravel have to be transported by road and by water ${ }^{(5)}$.

- Saving on energy and emissions concerning the production and transport of primary and secondary building materials for the construction of floors in buildings ${ }^{(5)}$.

This slab system could optimize the size of bearing walls and columns by reducingthe weight of slabs. Most slab are two-way members in buildings. Thus, it is important whether the BubbleDeck slab with plastic sphere voids acts like general reinforced concrete two-way slab or not ${ }^{(6)}$. To verify the flexural behaviors of this two-way BubbleDeck slab such as ultimate load capacity, service load deflection, concrete compressive strain and crack pattern, two-way flexural tests were performed by using a special loading frame.

\section{2- EXPERIMENTAL PROGRAM}

\subsection{Materials}

For the slab specimens, the design compressive strength of $33 \mathrm{MPa}$ was used. The concrete mixture proportions are presented in Table (1). For each series of casting, the specified compressive strength is measured by testing three concrete cylinders. Different sizes of reinforcing bars, 4 and $5 \mathrm{~mm}$ were used in the specimens. For each bar size, three samples were tested under tension. The yield and ultimate strength of different bars are given in Table (2). 
The plastic spheres used in this project are manufactured in Iraq (at AL-SABAH factory), from recycled plastic with different diameters of (64mm and $80 \mathrm{~mm})$. The purpose of using recycled material is to curb consumption of finite natural resources such as oil and minimize the burden on the environment through the cyclical use of resources, therefore the recycling martial reduces inputs of new resources and limits the burden on the environment and reduces the risks to human health.

\subsection{Test Specimens}

Test specimens were designed of six types of slabs, two were a conventional two-way R.C slab and the others were two-way BubbleDeck slabs. The test parameters included the ratio of bubble diameter $(\mathrm{B})$ to slab thickness $(\mathrm{H}),(\mathrm{B} / \mathrm{H})$. The parameters were as follows, the ratio of bubble diameter to slab thickness were $(0.51,0.64$ and 0.80$)$. Details and dimensions of the test specimens are illustrated in Table (3) and Figure (1).

The slab was simply supported at all edges by four steel beams which had a hinge in the upper surface to minimize fixed end moment and other errors from support condition during the test.

Specimens were tested under a five-point load system using a five hydraulic jack and a five loading plate to satisfy the actual loading condition (Figure (2)). The reasons of using special loading system which has five loading points with bearing were as follows. The loading condition of two-way slabs is distributed load in general buildings. And one point loading might cause punching failure at the loading point.

The deflection of the specimens was measured at their mid-span beneath the lower face of the tested slabs and the strain of the compressive side of the specimens was measured using DEMEC Strain Gages at nine points as shown in Figure (3). The load was increased gradually at increments of $(10 \mathrm{kN})$ to record the deflection up to failure.

\section{3- EXPERIMENTAL RESULTS}

\subsection{Ultimate Load Capacity}

The ultimate load capacity and the other results are tabulated in Table (4). The twoway BubbleDeck slab with the plastic sphere showed good ultimate load and ductility compared with the solid specimen. The ultimate total load of solid slabs (SD2 and SD3) were $(552 \mathrm{kN}$ and $707 \mathrm{kN})$ with the deflections of $(25.4 \mathrm{~mm}$ and $21.1 \mathrm{~mm})$. (BD2-bu64, BD2-bu80, 
BD3-bu64 and BD3-bu100) specimens showed $(550 \mathrm{kN}, 491 \mathrm{kN}, 704 \mathrm{kN}$ and $634 \mathrm{kN})$ with (27.0mm, 24.3mm, 23.0 and $20.5 \mathrm{~mm})$.

The important difference between solid and BubbleDeck slabs is stiffness. The stiffness of BubbleDeck slabs was slightly changed by the diameter of plastic sphere. As expected, BubbleDeck slab showed lower stiffness than solid specimen due to its lower cross section area. On the other hand (BD2-bu80 and BD3-bu100) showed a lower ultimate load than the solid specimen by about(10\%) and (BD2-bu64 and BD3-bu64) give the same ultimate load of the solid specimen, this due to reduce of concrete volume by (30\% and 25\%) due to plastic sphere in BubbleDeck slab specimens (BD2-bu80 and BD3-bu100) and (BD2bu64 and BD3-bu64), respectively.

\section{3-2 Load Versus Deflection Relationship}

Figures (4) and (5) shows the load versus mid-span deflection relationship of the slabs. It should be noted that the effect of the self weight of the test slabs is not included in the calculation of the test loads as it has negligible effect on the results. According to these, at earlier stages (i.e. before flexural cracking), the load-deflection curves are close to each other. With increasing load, the BubbleDeck specimens exhibited smaller stiffness. After yielding of reinforcing bars, the strength and stiffness of the BubbleDeck specimens were smaller compared to the control specimen (solid slab).

\subsection{Concrete Compressive Strain}

As shown in Figures (6) and (7), the BubbleDeck specimens give an increase in the concrete compressive strain over that of the reference solid specimen. This is due reduced concrete volume in the compression zone due to plastic spheres in BubbleDeck specimens.

\subsection{Crack Patterns}

Figures (8) and (9) illustrates the specimens' crack patterns and failure mode under ultimate load. All specimen showed flexural failure mode with diagonal flexural cracks. Some small longitudinal cracks appeared in (BD2-bu80 and BD3-bu100) specimens. This may be due to relatively thin bottom cover thickness between bottom of slab to bottom of void. As the thin part of the bottom cover concrete under the void was detached from the plastic sphere, small longitudinal crack occurred. 


\section{4- CONCLUSIONS}

Two-way BubbleDeck slabs with plastic sphere voids were tested in twodimensional flexural experiments, the following conclusions can be drawn:-

1. The stiffness values of BubbleDeck slabs were different from solid slab'. Especially, (BD2-bu80 and BD3-bu100) specimens which showed some one-way flexural cracks and lower stiffness. In view of the results so far achieved, two-way BubbleDeck slabs act like general solid R.C slabs basically and their flexural capacities were good enough to use.

2. The use of plastic spheres in reinforced concrete slabs $(B / H=0.51,0.64$ and 0.80$)$, had a result in comparison with reference solid slabs (without plastic spheres), bubbled slabs has $(100 \%, 100 \%$ and $90 \%)$ of the ultimate load of a similar reference solid slab but only $(76 \%, 75 \%$ and $70 \%)$ of the concrete volume due to plastic spheres, respectively.

3. The deflections under service load of BubbleDeck specimens were a little higher than those of an equivalent solid slab.

4. The concrete compressive strain of BubbleDeck specimens is greater than that of an equivalent solid specimen.

\section{5- REFERENCES}

1. J.H. Chung, B.H. Kim, H.K. Choi, S.C Lee and C.S. Choi: "Flexural capacities of hollow slab with material properties". Proceedings of the Korea Concrete Institute. Vol.22 No.1 2010 .

2. "BubbleDeck Slab Properties." BubbleDeck Voided Flat Slab Solution - Technical Manual and Documents, (2006).

3. J.H. Chung, N.K. Ahn, H.K. Choi. and C.S. Choi:" An analytical study of optimal hollow sphere shapes in hollow slab". Journal of the Korea institute for structural maintenance. 2009.

4. J.H. Chung, H.K. CHOI, S.C. LEE, J.K. Oh. and C.S. Choi: "An Analytical Study of the Impact of Hollow Sphere on Biaxial Hollow slab". Proceeding of annual conference of the architectural institute of Korea. 2009

5. Ing. A.C. Fuchs Deputy Director."BubbleDeck Floor System - An Iinnovative Sustainable Floor System" BubbleDeck Netherlands B.V., AD Leiden, The Netherlands, (2009). 
6. Schellenbach -Held, Stefan Ehmann, Karsten Pfeffer. "BubbleDeck - New Ways in Concrete Building”. Technical University Darmstadt's, Germany, (1998).

Table (1):- Concrete Mixture Design.

\begin{tabular}{|c|c|c|c|c|c|}
\hline \multirow{2}{*}{ Designation } & $\begin{array}{c}\text { Cement } \\
\left(\mathrm{kg} / \mathrm{m}^{3)}\right.\end{array}$ & \multicolumn{2}{|c|}{ Aggregate $\left(\mathrm{kg} / \mathrm{m}^{3}\right)$} & \multirow{2}{*}{$\begin{array}{c}\text { w/c Ratio to Give } \\
\text { Slump }\end{array}$} \\
\cline { 3 - 4 } & Sand & Coarse & & $140 \pm 10 \%$ \\
\hline $\mathrm{C} 33$ & 425 & 735 & 1015 & 225 & 0.53 \\
\hline
\end{tabular}

* Maximum size of aggregate was $10 \mathrm{~mm}$

Table (2):- Test Result of Reinforcing Bars.

\begin{tabular}{|c|c|c|c|c|}
\hline $\begin{array}{c}\text { Nominal Diameter } \\
(\mathrm{mm})\end{array}$ & $\begin{array}{c}\text { Measured Diameter } \\
(\mathrm{mm})\end{array}$ & $\begin{array}{c}\text { Area } \\
\left(\mathrm{mm}^{2}\right)\end{array}$ & $\begin{array}{c}\mathrm{f}_{\mathrm{y}} \\
(\mathrm{MPa})\end{array}$ & $\begin{array}{c}\mathrm{f}_{\mathrm{u}} \\
(\mathrm{MPa})\end{array}$ \\
\hline 4 & 4 & 12.566 & 557 & 835 \\
\hline 5 & 4.994 & 19.588 & 663 & 817 \\
\hline
\end{tabular}

Table (3): Properties of Slab Specimens.

\begin{tabular}{|c|c|c|c|c|c|c|c|c|c|}
\hline No. & $\begin{array}{l}\text { Specimen } \\
\text { name }\end{array}$ & $\begin{array}{l}\text { Length } \\
\text { (mm) }\end{array}$ & $\begin{array}{l}\text { Width } \\
(\mathrm{mm})\end{array}$ & $\begin{array}{c}\text { Slab } \\
\text { thickness } \\
\mathrm{H}(\mathrm{mm})\end{array}$ & $\begin{array}{c}\text { Bubble } \\
\text { diameter } \\
\text { B }(\mathrm{mm})\end{array}$ & $\mathrm{B} / \mathrm{H}$ & $\begin{array}{l}\text { No. of } \\
\text { plastic } \\
\text { spheres }\end{array}$ & $\mathrm{f}_{\mathrm{c}}^{\prime}(\mathrm{MPa})$ & $\rho(\%)$ \\
\hline 1 & SD2 & \multirow{6}{*}{1000} & \multirow{6}{*}{1000} & \multirow{3}{*}{100} & - & - & -- & 33.13 & \multirow{3}{*}{0.443} \\
\hline 2 & BD2-bu 64 & & & & 64 & 0.64 & 144 & 34.66 & \\
\hline 3 & BD2-bu 80 & & & & 80 & 0.80 & 100 & 33.34 & \\
\hline 4 & SD3 & & & \multirow{3}{*}{125} & -- & - & - & 32.14 & \multirow{3}{*}{0.285} \\
\hline 5 & BD3-bu 64 & & & & 64 & 0.51 & 144 & 34.66 & \\
\hline 6 & BD3-bu100 & & & & 100 & 0.80 & 64 & 33.34 & \\
\hline
\end{tabular}

Table (4): Test Results.

\begin{tabular}{|c|c|c|c|c|c|c|c|}
\hline Slab name & $\begin{array}{c}\text { Weight } \\
(\mathrm{kg})\end{array}$ & $\begin{array}{c}\% \\
\text { Decrease in } \\
\text { Weight }\end{array}$ & $\begin{array}{c}\text { Pu }(\mathrm{kN}) \\
\text { Ultimate } \\
\text { Load }\end{array}$ & $\begin{array}{c}\Delta_{0.7 \mathrm{Pu}} \\
(\mathrm{mm})\end{array}$ & $\begin{array}{c}\% \\
\text { Increase } \\
\text { in } \Delta_{0.7 \mathrm{Pu}}\end{array}$ & $\begin{array}{c}\Delta_{\mathrm{u}}(\mathrm{mm}) \\
\text { Ultimate } \\
\text { Deflection }\end{array}$ & $\frac{F_{u}}{\boldsymbol{F}_{\text {u solid }}} \%$ \\
\hline SD2 & 253 & --- & 552 & 9.8 & --- & 25.4 & 100 \\
\hline BD2-bu64 & 190 & 25 & 550 & 11.5 & 17 & 27.0 & 100 \\
\hline BD2-bu80 & 179 & 29 & 491 & 12.5 & 28 & 24.3 & 89 \\
\hline SD3 & 314 & --- & 707 & 9.1 & --- & 21.1 & 100 \\
\hline BD3-bu64 & 240 & 24 & 704 & 10.3 & 13 & 23.0 & 100 \\
\hline BD3-bu100 & 221 & 30 & 634 & 12 & 32 & 20.5 & 90 \\
\hline
\end{tabular}




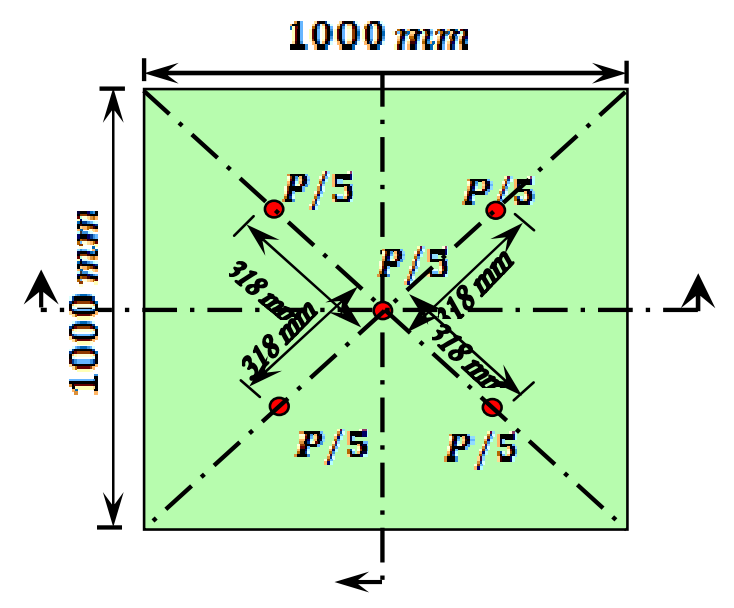

(a) Top View of Tested Slab

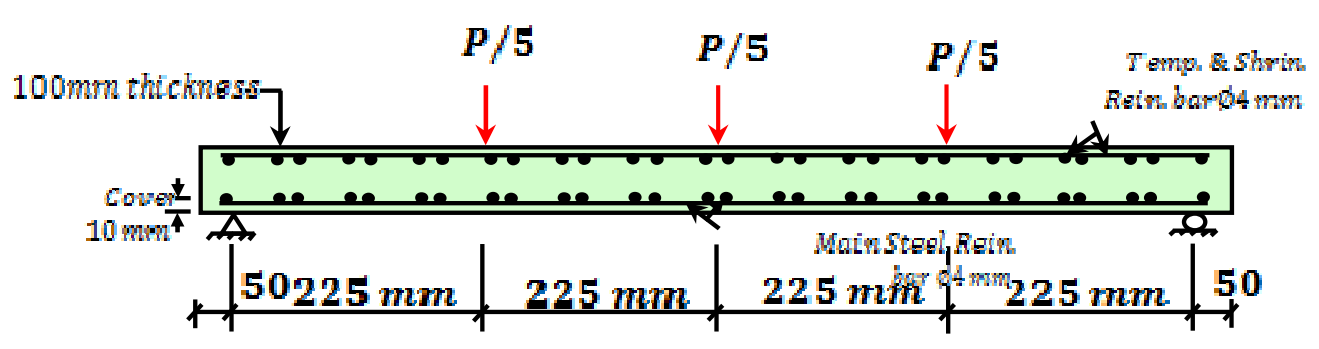

(b) Cross-Section in Solid Slab.

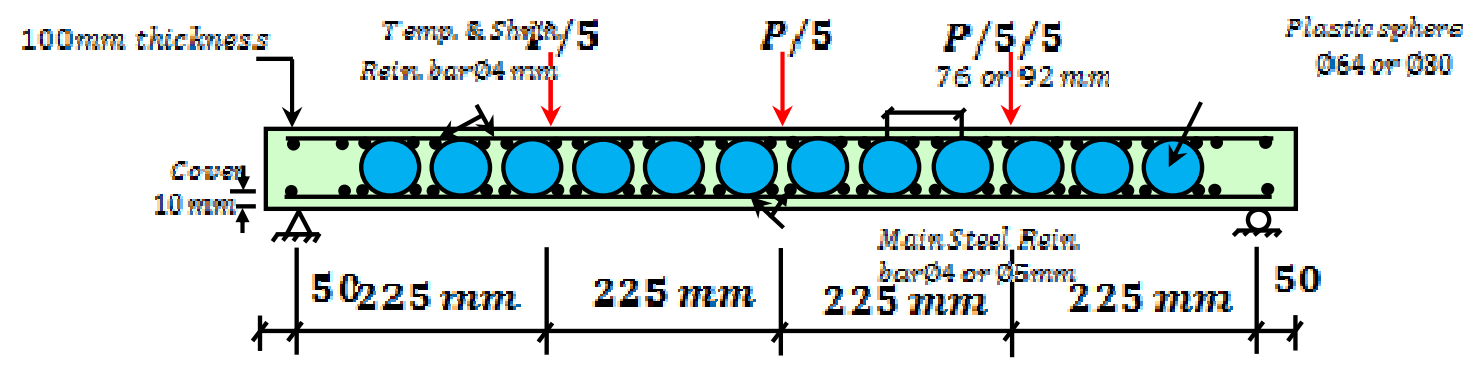

(c) Cross-Section in BubbleDeck Slab.

Fig.(1): Details and Dimensions of Test Slab Specimens. 

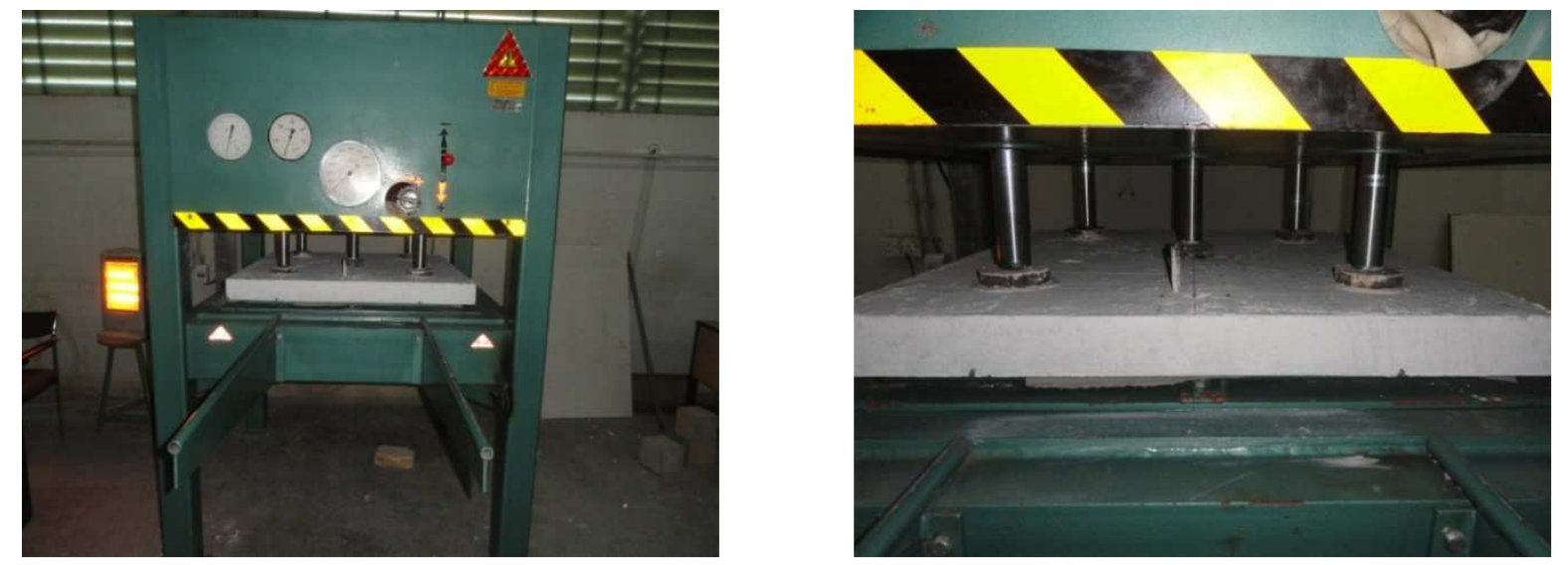

Fig. (2):- Test Configuration of Two-Way BubbleDeck Slab.

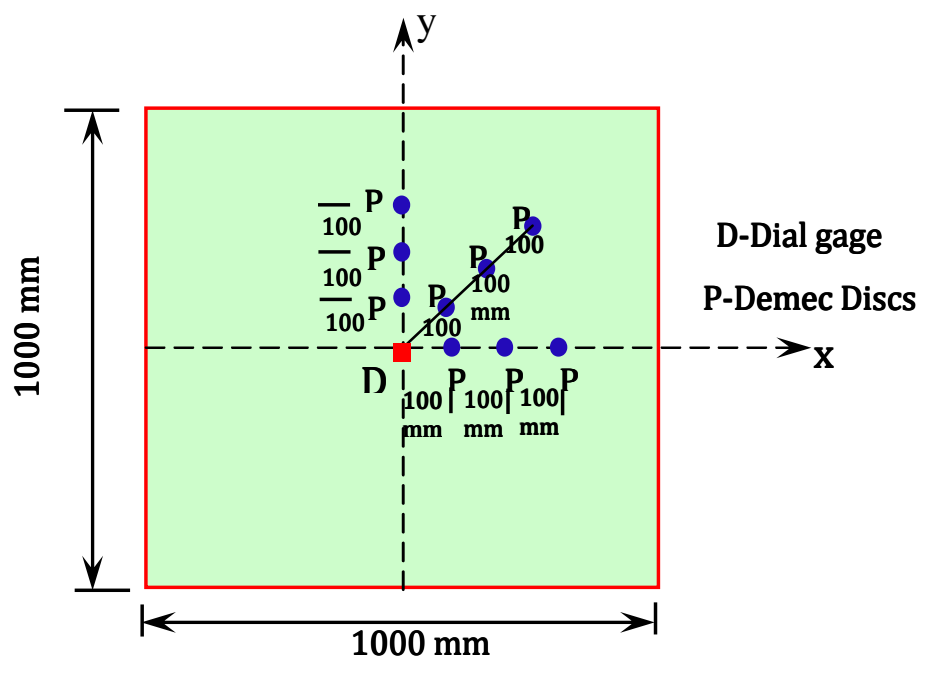

Fig. (3):- Positions of Dial Gages and Demec Discs.

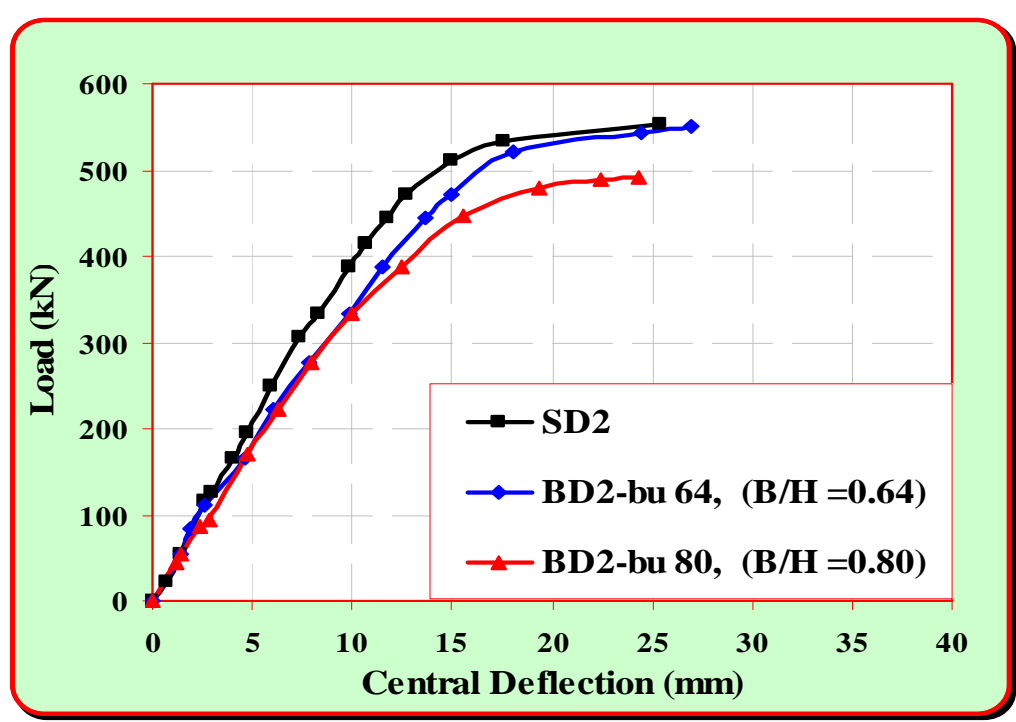

Fig. (4):- Load Versus Deflection Relationship (H=100mm). 


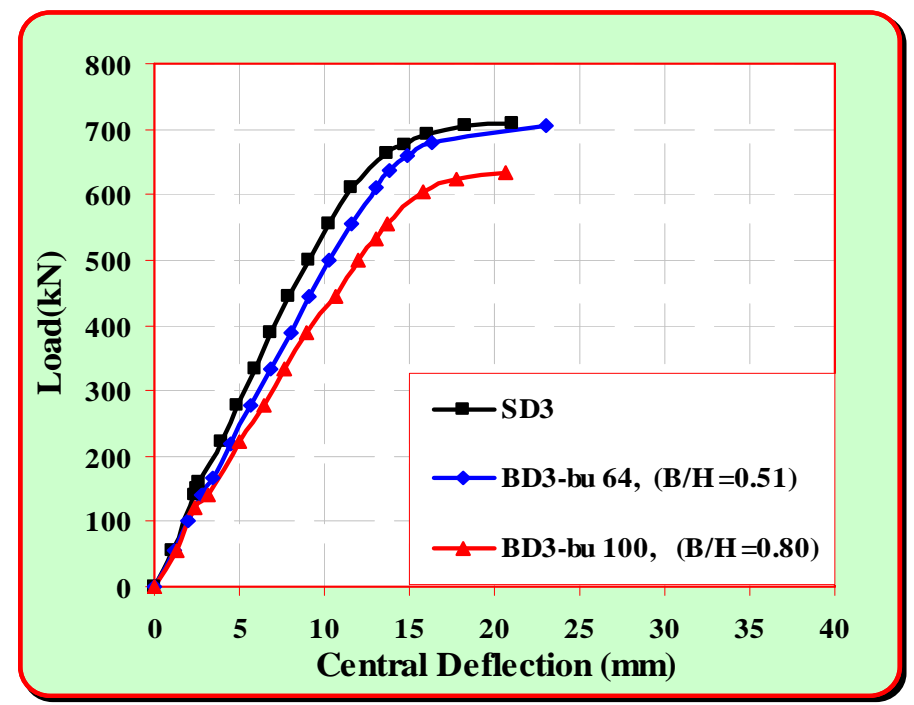

Fig.(5):- Load Versus Deflection Relationship ( $\mathrm{H}=125 \mathrm{~mm})$.

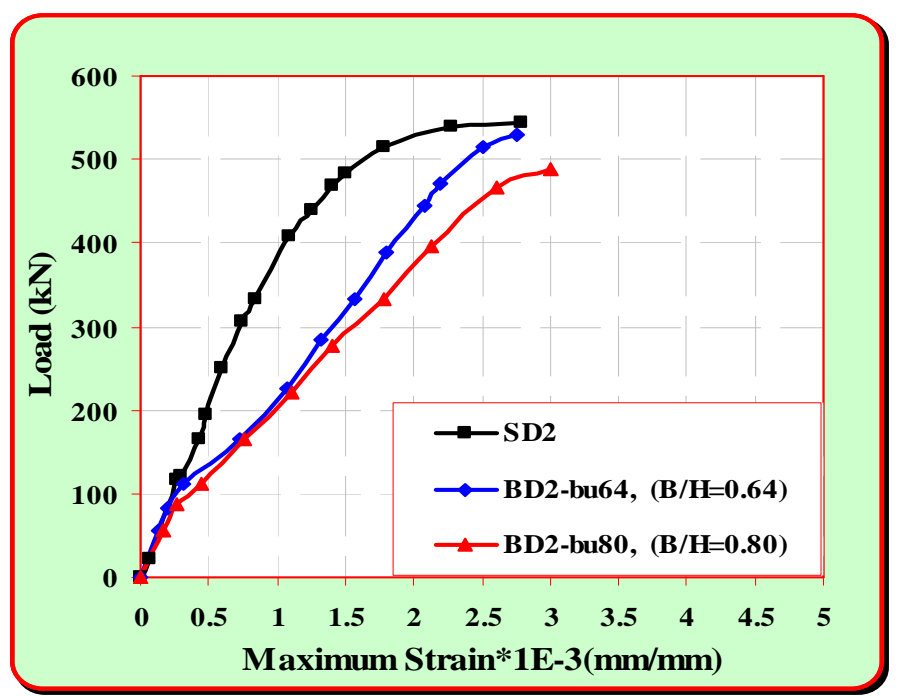

Fig.(6):- Load-Maximum Concrete Compressive Strain Curve (H=100mm).

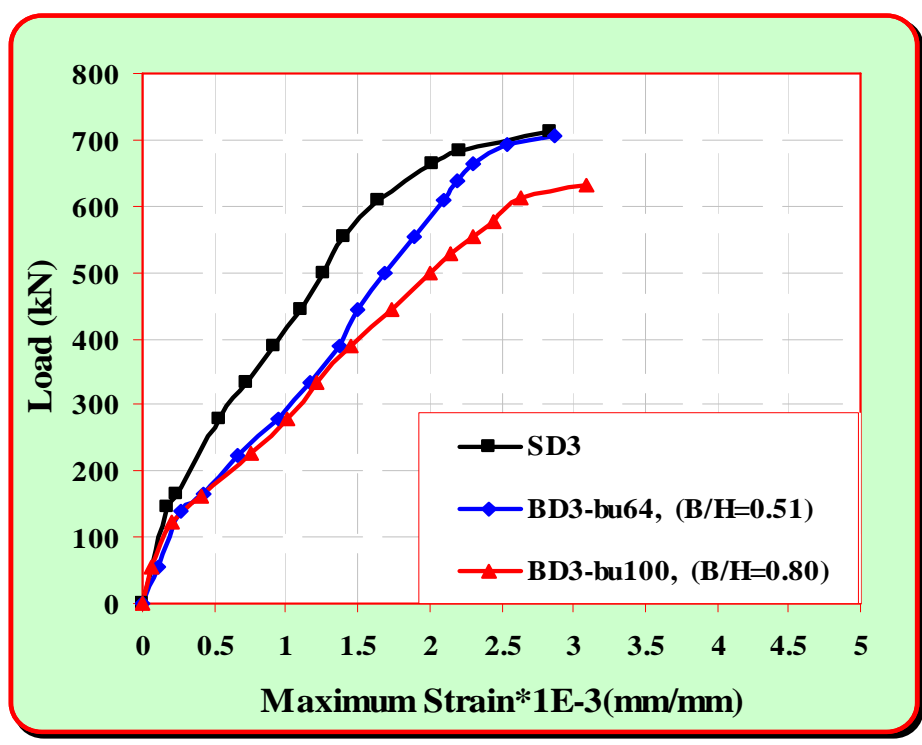

Fig. (7):- Load-Maximum Concrete Compressive Strain Curve (H=125mm). 


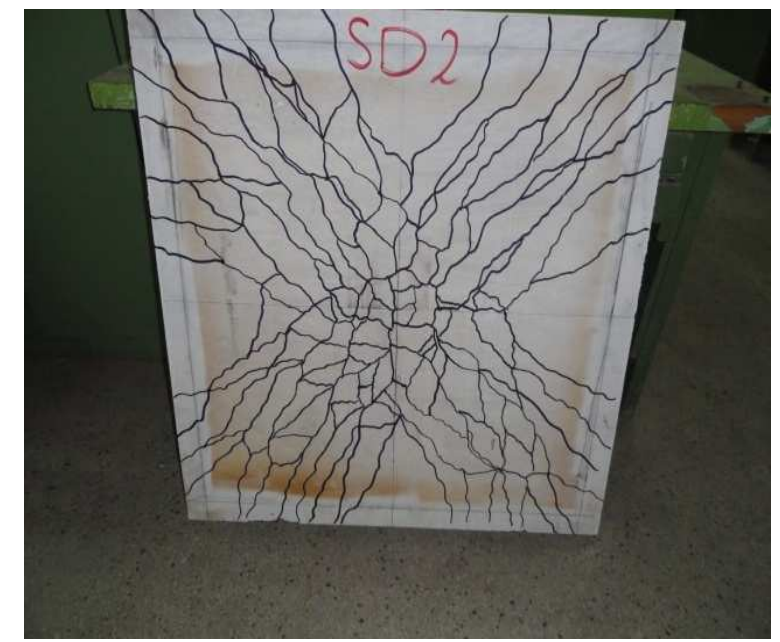

(a) $\mathrm{SD} 2$

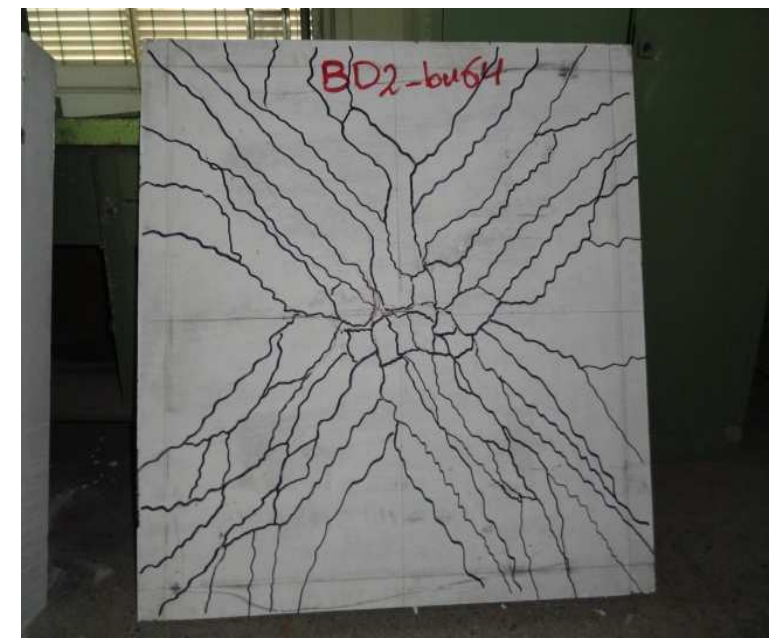

(b) BD2-bu64

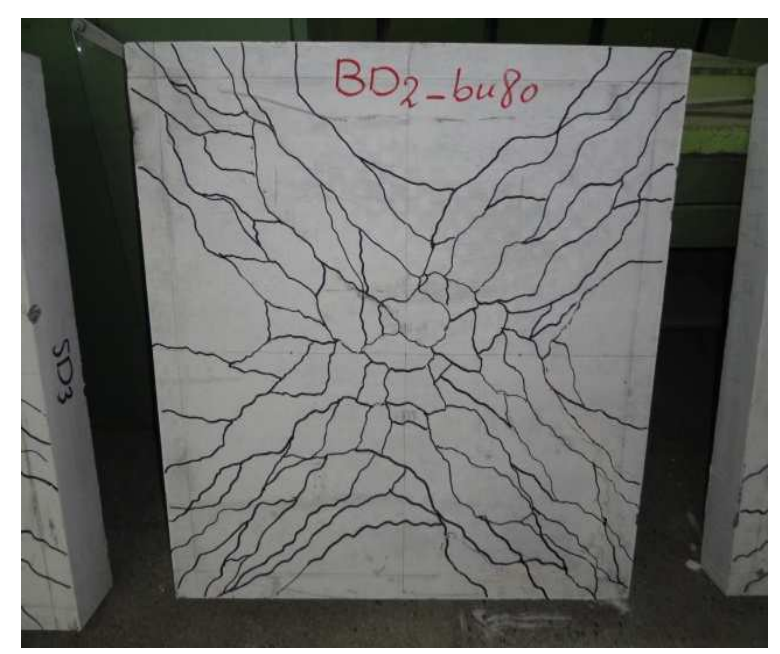

(c) BD2-bu80

Fig.(8):- Crack Patterns (H=100mm). 


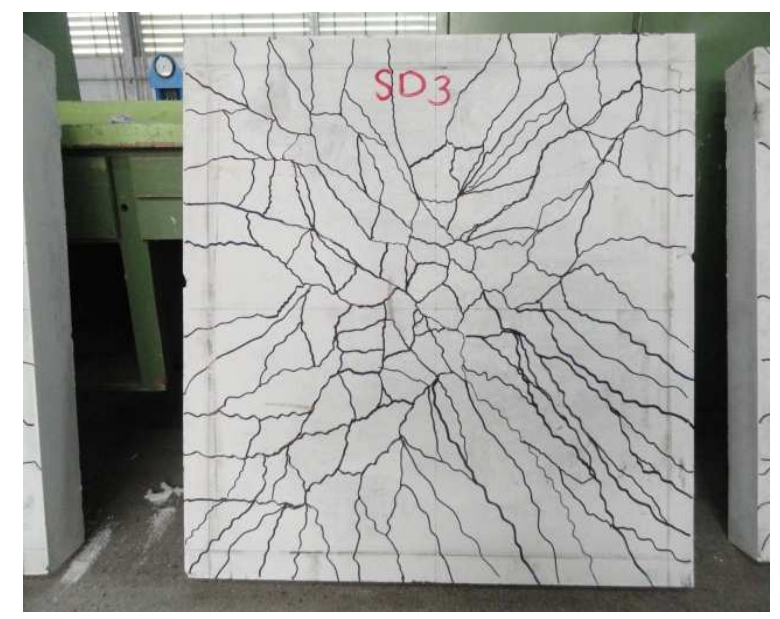

(a) SD3

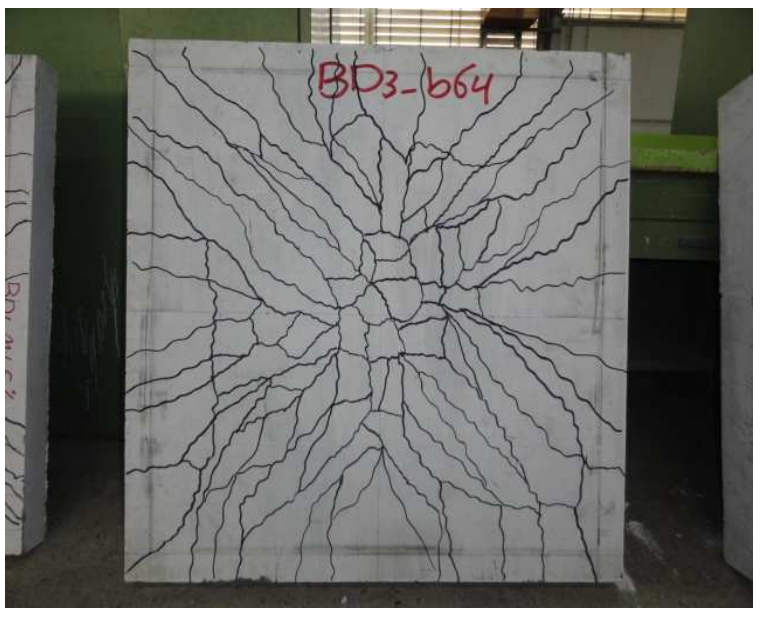

(b) BD3-bu64

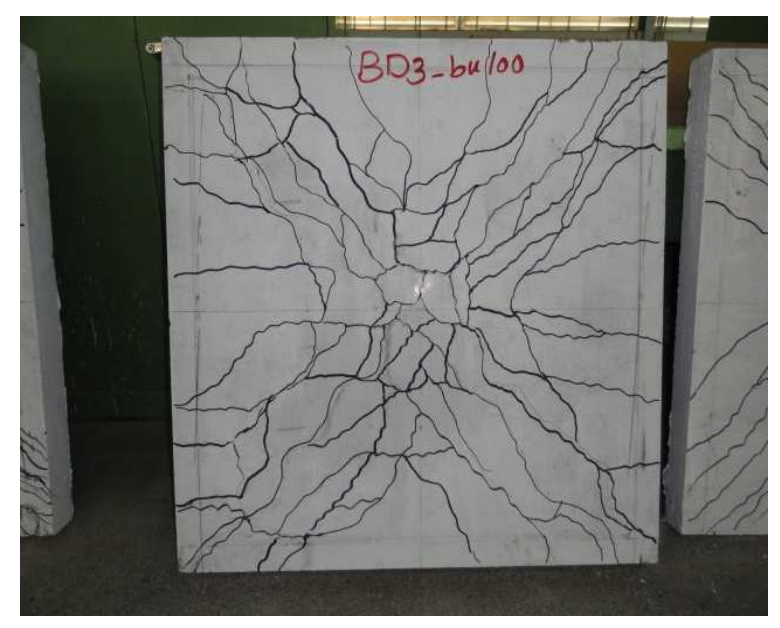

(c) BD3-bu100

Fig. (9):- Crack Patterns ( $\mathrm{H}=125 \mathrm{~mm})$. 


\section{تحمل الانثاء للبلاطات الخرسانية المسلحة ذات البعدين والحاوية على كرات بلاستيكية مجوفة}

\author{
وسام داود سلمان \\ مدرس مساعد \\ كلية الهندسة_ جامعة ديالى مدرئ مدئ
}

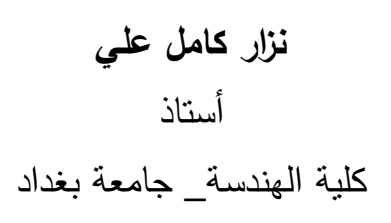

عامر محمد إبراهيم

أستاذ محمد إبراذ

كلية الهندسة _جامعة ديالى

\section{الخلاصة}

يهتم هذا البحث بدراسة تحمل الانثاء ثنائي المحور للبلاطات الحاوية على كرات بلاستيكية مجوفة والمعروفة بنظام

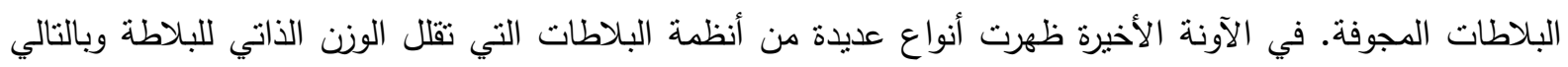

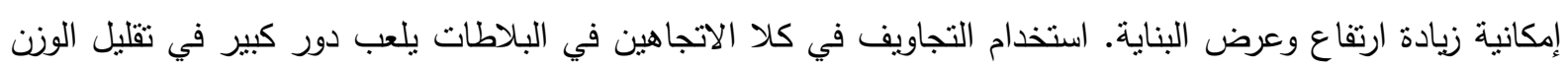

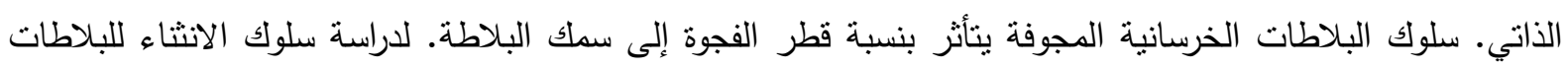

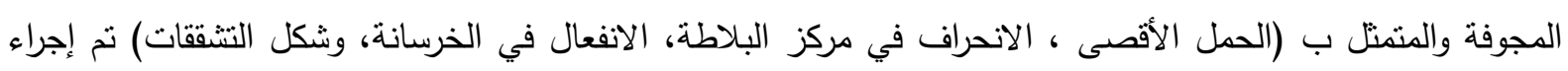

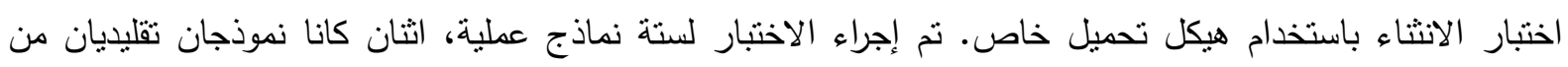

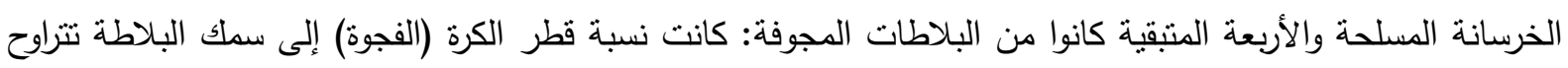

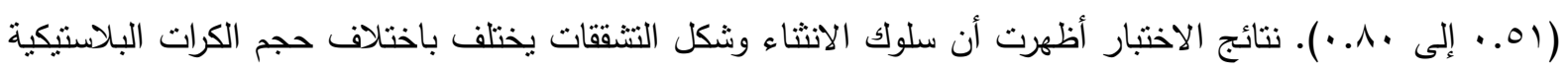

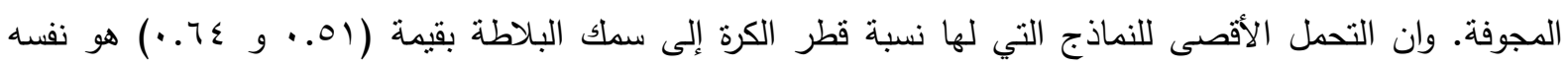

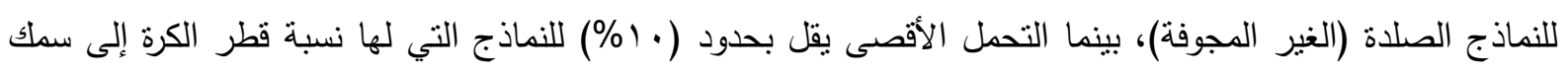
البلاطة بقيمة (•^. • ( ). 